\title{
Peña Ardid, Carmen (ed.) (2019): Historia cultural de la transición. Pensamiento crítico y ficciones en literatura, cine y televisión. Madrid: Los Libros de la Catarata,270 pp. ISBN: 978-84-9097-667-0.
}

El proceso de transición política a la democracia en España, "la Transición", está sufriendo una revisión profunda desde el ámbito académico durante los últimos años. En torno a la Transición, en la actualidad, coexisten, al menos, dos grandes relatos. El primero es el oficialista. Desde esa perspectiva el cambio político fue un proceso dirigido por las elites políticas que, captando el sentir popular, permitió acordar un cambio de régimen político pacífico y pactado entre las fuerzas de la dictadura y las de la oposición. Este proceso implicó el olvido, más o menos voluntario del pasado, y una suerte de orientación del presente y, sobre todo, del futuro. Los diferentes "pecados" de las elites dirigentes de régimen franquista fueron minimizados, cuando no ignorados, y al mismo tiempo, se permitió, desde una suerte de condescendencia tolerante, la integración de los perdedores de la guerra y de sus herederos en el nuevo sistema político democrático.

Esta versión oficial, de la que son un magnifico exponente los famosos documentales relativos a la Transición de la periodista Victoria Prego, ha sido el relato hegemónico durante décadas, repetido hasta la saciedad por los medios de comunicación y la historiografía oficial. La Transición, así contada, se convirtió incluso, en un caso de estudio académico que debía ser exportado, que se planteaba como la vía idónea para la transformación de los regímenes dictatoriales hacia sistemas democráticos en todo el planeta: desde el régimen sudafricano del apartheid, pasando por los países de la órbita de la extinta Unión Soviética y, sobre todo, y en especial, de cara a las transiciones en América Latina.

Frente a esa versión ha ido surgiendo otra, que ha ido consolidado especialmente tras la crisis económica del año 2008, una especie de narración a la contra que ve en términos menos positivos el proceso de cambio de la dictadura a la democracia. Para esa corriente de análisis el proceso que lleva a la aprobación de la Constitución Española de 1978 pierde esta denominación para calificarse como "Régimen del 78" o "Restauración borbónica". El planteamiento a la hora de analizar el proceso es radicalmente distinto. La Transición así considerada, nos recalcan que en ningún caso fue un proceso pacífico, sino marcado por la violencia, tanto por parte del Estado como de otros actores políticos, se plantea, abiertamente que la Transición fue, en buena medida, una respuesta a las presiones populares para alcanzar mayores niveles de democratización y que sin éstas la Transición no se hubiera producido.

Según esta interpretación, las elites de la dictadura franquista consiguieron salir claramente beneficiados del proceso de democratización, ya que por un lado, blanquearon sus "pecados" y, por otro, crearon un régimen que, en gran manera, sellaba su impunidad, impidiendo revisar su actuación política y económica previa. La oposición se vio así forzada a aceptar esta componenda, especialmente los partidos de izquierda, y el pueblo fue utilizado más como una coartada, un mero convidado de piedra, instrumentalizado, que como lo que debió ser: un actor político de primer orden al que se tuviese realmente en consideración. De hecho, estos estudios sostienen que una de las primeras medidas de los partidos políticos legalizados en el nuevo régimen democrático fue la desactivación de los movimientos políticos de raíz más popular.

En esta revisión del proceso de cambio político, que es también una revisión por parte de una nueva generación sobre el papel histórico jugado por las generaciones que los precedieron, todas sus dimensiones son sometidas, al que se considera, imprescindible escrutinio público. La cultura es una de ellas. La Profesora de la Universidad de Zaragoza, Carmen Peña Ardid, coordina una obra que analiza diversos aspectos de las transformaciones y del legado de la cultura de La Transición española a la democracia. Pretende ser una aproximación académica a la historia cultural de La Transición, y en esa línea los textos incluidos en la obra incluyen un abundante aporte bibliográfico, muy estimable.

Aunque, como es habitual en este tipo de obras colectivas, existe cierta diferencia en la profundidad y calidad de las aportaciones de los diversos autores, el tono general del libro resulta estimulante y rico, nos acerca a los debates en torno a los principales aspectos de la cultura durante este periodo de la historia de nuestro país. Un periodo tremendamente sugestivo para cualquier lector atento.

Tras la introducción general de la editora, se pasan a analizar aspectos concretos. El primer capítulo describe como algunos de los más destacados intelectuales del régimen franquista -a los que Francisco Umbral llamaba los "Laines" - todos ellos vinculados originalmente a la Falange, iniciaron un giro personal para adaptarse al nuevo ambiente político. Sus memorias son una buena muestra de esta transformación, oportunista o sentida, según el análisis del lector, desde posición es que se situaba en la defensa de la dictadura, legitimando el sistema franquista. Intelectuales en muchos casos de raíces fascistas y autoritarias comprometidos con el régimen. A intelectuales liberales, e incluso izquierdistas, demócratas "de toda la vida", según los términos empleados en la época, capaces de lavar su imagen con mayor o menor descaro. El segundo capítulo analiza el papel de los intelectuales de la generación del 1950 que 
se habían enfrentado a la Dictadura, como Agustín García Calvo o Rafael Sánchez Ferlosio -hijo este último de Rafael Sánchez Mazas, uno de los primeros ideólogos de la Falange-, en los nuevos medios de la democracia, en especial en el periódico El País.

En los capítulos tercero y cuarto se describe la recepción de la Transición en la novela española de la época. El tercero analiza su impacto en la novela de los años inmediatamente posteriores, y el cuarto, el resto de la incorporación del análisis de la Transición en la novela del siglo $\mathrm{XXI}$, en una narración sugerente. Es decir, en cierta forma se contrapone el relato de aquella generación que la vivió en primera persona, que protagonizó la Transición, con la narración de una nueva generación que la va percibiendo como una cosa de sus padres y abuelos que, por otro lado, creen que propenden a la idealización. El siguiente capítulo se centra en la Transición en la novela negra. Los capítulos sexto y séptimo se centran en su impacto en el teatro.

Los textos, hasta este punto de la obra, mantienen un cierto afán de sistematicidad, esto es, tratan de mostrar el impacto de la Transición en la literatura o el teatro en su conjunto. Tras ese estudio, de carácter más sistemático como hemos señalado, se nos presentan, en el resto de los capítulos de un modo más puntual aspectos concretos de la cultura de la Transición: la sexualidad en el cine (cap. 8), la presencia de la Transición en la película La Isla Mínima (cap. 9), los programas documentales sobre la Transición en la televisión (cap. 10), en dos series de ficción televisiva: Pepe Carvalho y Pájaro en la tormenta (cap. 11), sobre la compañía Dagoll Dagom (cap. 12), un capítulo de la serie El Ministerio del Tiempo sobre el Guernica (cap. 13), y la ficción televisiva elaborada por mujeres como Pilar Miró, Josefina Molina y Lola Salvador (cap. 14).
En este sentido, el libro va de más a menos en ese afán de sistematicidad. Tal vez no pueda ser de otra forma cuando se intenta recoger un análisis tan amplio de la cultura de una etapa histórica en su conjunto. Siempre habrá aspectos de la realidad estudiada que se escapen, o para los que, simplemente, no haya lugar. Así, nada se dice sobre el papel clave de la Transición en la música popular, en el cómic o, entre otros aspectos relevantes, en la floreciente cultura juvenil de la época. También podría haberse incluido un capítulo sobre las industrias culturales y el consumo cultural en el periodo estudiado, que hubiese enmarcado, con datos cuantitativos, los posteriores análisis cualitativos. Pero esto no son sino sugerencias, apuntes, glosas que en ningún caso desmerecen el valor de la obra. Nos encontramos ante un libro que viene a mostrar el creciente interés por la Transición como un periodo clave de la historia reciente de España. Una obra que puede servir como recio contraste, al mostrar una imagen más ponderada y distante de la cultura en la Transición, frente a las revisiones marcadamente más críticas sobre esa etapa

Juan Carlos Cuevas Lanchares

(D) https://orcid.org/0000-0002-1871-9107 Universidad Complutense de Madrid, España jccuevas@ucm.es

Recibida: 05-02-2020

Aceptada: 30-03-2020 